\title{
Peri Operative Management of a Simultaneously Symptomatic Diaphragmatic Hernia and Imperforate Anus in a Neonate: A Rare but Challenging Combination
}

\author{
Ashani Ratnayake ${ }^{1 *}$, PDRS Kumar ${ }^{2}$ and Sakunthala Peiris ${ }^{3}$ \\ ${ }^{1}$ Consultant Anaesthetist, Base Hospital, Sri Lanka \\ ${ }^{2}$ Consultant Paediatric Surgeon, National Hospital, Sri Lanka \\ ${ }^{3}$ Consultant Anaesthetist, National Hospital, Sri Lanka
}

*Corresponding author: Ashani Ratnayake, Consultant Anaesthetist, base Hospital, Sri Lanka.

To Cite This Article: Ashani Ratnayake, PDRS Kumar, Sakunthala Peiris. Peri Operative Management of a Simultaneously Symptomatic Diaphragmatic Hernia and Imperforate Anus in a Neonate: A Rare but Challenging Combination. Am J Biomed Sci \& Res. 2021 - 14(2). AJBSR. MS.ID.001969. DOI: 10.34297/AJBSR.2021.14.001969.

Received: 眥 September 12, 2021; Published: 眥 September 17, 2021

\begin{abstract}
Congenital diaphragmatic hernia a rare congenital malformation which often requires surgical interventions. The surgery is not an emergency, and it can be done within days with planned preoperative optimisation. We present a case of a premature neonate presented with co-existence of left side diaphragmatic hernia with imperforate anus. Presence of imperforate anus prevents the passage of meconium leading to distention of bowel increasing the resistance inside the left hemithorax. Therefore, an urgent repair of the diaphragmatic hernia with colostomy formation was done under general anaesthesia after 48 hours of birth. Patient was managed in a paediatric intensive care unit both pre and post operative period. Even though the post operative period was complicated with a broncopneumonia and a pleural effusion, he was discharged from ICU 20 days after the procedure.
\end{abstract}

Keywords: Congenital Diaphragmatic Hernia; Imperforate Anus; Neonatal ICU Care

\section{Introduction}

Congenital diaphragmatic hernia (CDH) is a rare condition with an incidence of 1 in 2000-4000 live births [1]. Imperforate anus carries a prevalence of 1 in 12000 [2]. The coexistence of these two conditions is extremely rare although certain other congenital abnormalities like cardiac abnormalities, musculoskeletal abnormalities and renal abnormalities have been described along with CDH. Out of the reported cases, none of the neonates survived the initial course of management. The presence of one condition alters the plan of management of the other condition. We report a case of successful management of a neonate who had both abnormalities which became symptomatic at the early neonatal period.

\section{Case Report}

A 31-year-old primi delivered a neonate weighing $1.8 \mathrm{kgs}$ at a gestational age of 32 weeks and 2 days after emergency caesarean section due to premature rupture of membranes. Antenatal ultrasound scans reveals no abnormalities. His APGAR score was 7 at birth and 8 at 10 minutes. He developed an apnoeic attack with absent air entry on left side. Heart sounds were better heard on right side. He had an imperforate anus (Figure 1) with a mildly distended abdomen (Figure 2). A tentative diagnosis of diaphragmatic hernia associated with imperforate anus was made. The baby was intubated and ventilated. A chest Xray was taken after inserting a nasogastric tube, confirmed the diagnosis of left 
sided diaphragmatic hernia (Figure 3). A chest Xray was taken after inserting a nasogastric tube, confirmed the diagnosis of left sided diaphragmatic hernia (Figure 3). The neonate was continued on ventilatory support with intravenous $\mathrm{MgSO}_{4}$ and NG Sildenafil for the management of persistent pulmonary hypertension which is common in this population. On day 2 he was started on inotropic support with IV Dobutamine. Echocardiogram showed a patent foramen ovale with mild to moderate pulmonary hypertension. The NG tube remained on drainage while maintaining hydration through intra venous maintenance fluid infusion. Patient had a pre ductal saturation of $97 \%$. Arterial blood gas showed a metabolic acidosis with a $\mathrm{P}^{\mathrm{H}}$ of 7.2 with a $\mathrm{HCO}_{3}$ of $11 \mathrm{mmol} / \mathrm{l}$. This was corrected with IV $\mathrm{Na} \mathrm{HCO}_{3}$.

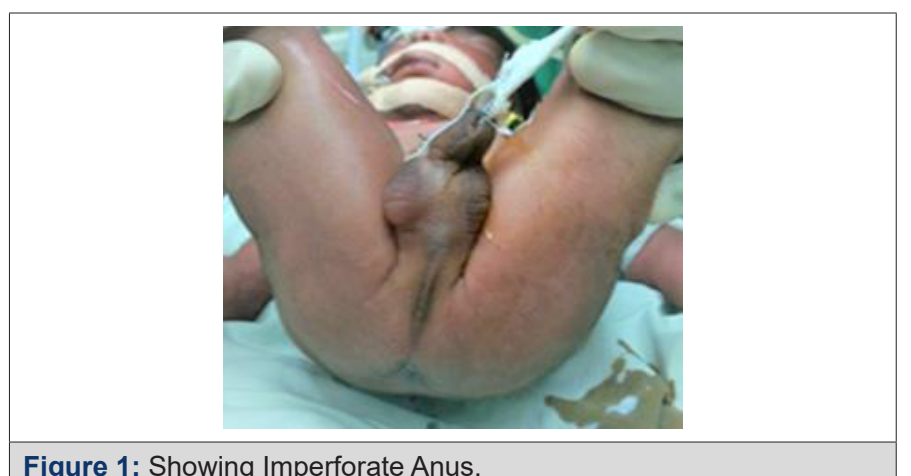

Figure 1: Showing Imperforate Anus.

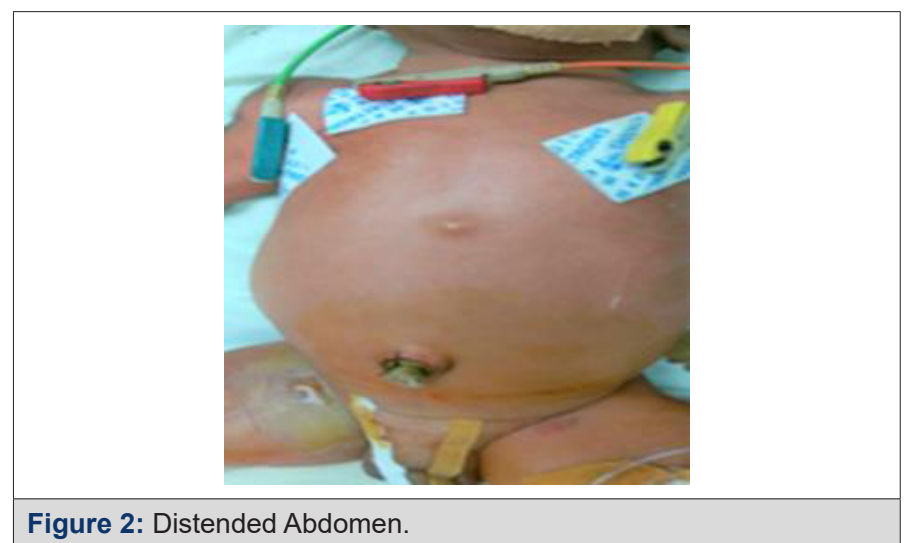

Figure 2: Distended Abdomen.

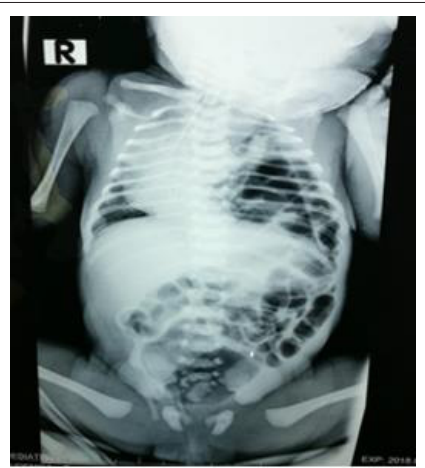

Figure 3: $\mathrm{X}$ ray of chest and abdomen showing presence of bowel loops in the left side of the chest suggestive of $L$ sided diaphragmatic hernia.
He had a lactate level of $4.5 \mathrm{mmol} / \mathrm{l}$ with a urine out put more than $1 \mathrm{ml} / \mathrm{kg} / \mathrm{hr}$. The ventilatory requirements remained static, but the increase in abdominal distension was noted. Therefore, a decision was made to go ahead with the surgical correction. During this this time he fulfilled the criteria for CDH EURO consortium except high lactate level. 48 hours after birth repair of congenital diaphragmatic hernia ( $\mathrm{CDH}$ ) and colostomy creation was done under general anaesthesia. Diaphragmatic defect was identified (Figure 4) and the stomach, spleen and all the intestines were gently reduced into the peritoneal cavity and tension free primary closure was done. The blind end of rectosigmoid colon with proximal distension was found in the low pelvis (Figure 5) and the distended bowel 1 sigmoid colostomy was created in left iliac fossa. Patient was on inotropic support during first five days after surgery. The ventilatory requirements increased in the immediate post operative period, with a left sided pleural effusion which was managed with an intercostals tube. Patient required prolong ventilatory support with the development of pleural effusion and bronchopneumonia. He also required intermittent high frequency oscillatory ventilatory support. Successful extubation was done on day 20. Patient was discharged to high dependency unit on day 26. At the time of discharge his weight was $2.1 \mathrm{~kg}$. He was discharged from the ward after a total stay of 42 days. Abdomino-perineal pullthrough procedure for imperforate anus was planned.

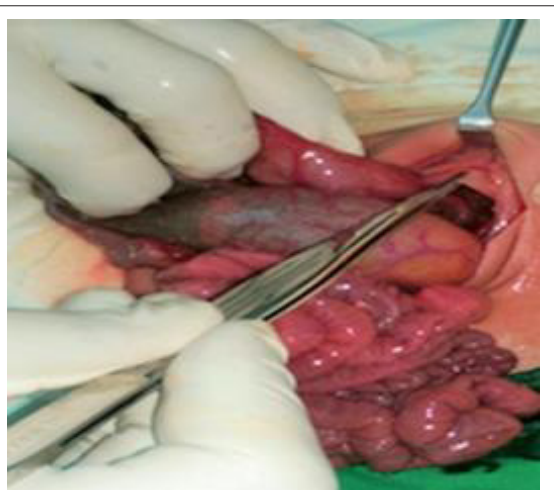

Figure 4: Forceps pointing at the diaphragmatic defect.

\section{Discussion}

$\mathrm{CDH}$ is a rare condition with an incidence of 1 in 2000-4000 live births [1]. Imperforte anus carries a prevalence of 1 in 12000 [2]. The coexistence of these two conditions is extremely rare although certain other congenital abnormalities like cardiac abnormalities, musculoskeletal abnormalities and renal abnormalities have been described along with $\mathrm{CDH}$. Farhadi, et al. [2] reported a case of the coexistence of these 2 conditions which ended up with case fatality due to pulmonary haemorrhages without undergoing surgical intervention $[2,3]$ reported another case of a patient with $\mathrm{CDH}$, imperforate anus along with pulmonary sling complex and a horse shoe kidney. In their report, $\mathrm{CDH}$ had a late and delayed 
presentation at 4 months of age when the infant was admitted for a definitive laparoscopic assisted pull through operation [3]. There are case reports of CDH associated with VACTERL anomaly (Vertibral, Anorectal, Cardiac, Tracheo-oesophageal, Renal and Radial Limb anomalies) and imperforate anus was found to be one of the multiple abnormalities. Chen et al described a neonate with VACTERL association and right sided CDH [4]. Our case is unique as we report a successful surgical management of a patient in whom there was a simultaneously symptomatic $\mathrm{CDH}$ and Imperforate Anus. CDH alone is not a surgical emergency, and the current practice is to allow the patient to be stabilised prior to surgical correction.

Meanwhile, they pass meconium and keep the bowel decompressed. But the presence of imperforate anus prevents bowel decompression and interferes mechanically with the lung expansion as meconium and air loaded colon fills the left hemithorax. Further, the intestinal obstruction due to imperforate anus must be corrected before it leads to colonic perforation. The $\mathrm{CDH}$ EURO consortium had suggested the criteria to be fulfilled prior to undergo correction of $\mathrm{CDH}$ [5]. These includes, mean arterial pressure normal for gestation, preductal oxygen saturation of consistently 85-95 on $\mathrm{FiO}_{2}<0.5$, lactate below $3 \mathrm{mmol} / \mathrm{l}$ and urine output more than $1 \mathrm{ml} / \mathrm{kg} / \mathrm{hr}$. Our patient fulfilled all these except the lactate levels. Our initial plan was to do only a loop colostomy to decompress bowel if we could not meet criteria for corrective surgery for imperforate anus. Since this baby did not show features of low imperforate anus, perineal surgery was not an option. Chest drainage following CDH repair is not routine. Transient effusion and/or pneumothorax is often encountered until full expansion of the lung. But in this patient the pleural effusion was large and led to respiratory compromise. Therefore, intercostal drainage was needed. When rare combinations of defects are encountered, the guidelines for management of individual defects might be at variance with one another as in this case. We believe this case report will be useful in the management of similar cases and preoperative counselling of such patients.

\section{Conclusion}

Neonatal surgeries for the correction of congenital abnormalities are often challenging due to different physiological conditions. A combination of 2 challenging congenital abnormalities often needs careful planning from the surgical, anaesthetics and critical care teams. The outcome of this case was successful because of the careful planning and timely interventions of the congenital abnormalities and numerous complications following its repair.

\section{References}

1. Christopher Rouse, Luke Schmidt, Lee Brock, Angela Fagiana (2017) Congenital Diaphragmatic Hernia Presenting in a 7-Day-Old Infant. Case Reports in Emergency Medicine 10: 3.

2. Farhadi R, Nakhshab M (2016) Association of imperforate anus and congenital diaphragmatic hernia in one of a twins who conceived by Assisted Reproductive Technology (ART). Caspian Pediatr 2(1): 127130.

3. Walters D, Burjonrappa S, Chun K (2011) Imperforate anus, diaphragmatic hernia, horseshoe kidney and pulmonary sling complex: case description. J PediatrSurg 46(9): 5-7.

4. Chen RH, Hung HY, Wang NL Haw-Kwei Hwang, Shin-Lin Shih, et al. (2013) VACTERL association complicated with right-sided congenital diaphragmatic hernia. PediatrNeonatol 57(4): 347-350.

5. M Quinney, H Wellesely (2018) Anaesthetic management of patients with congenital diaphragmatic hernia. BJA education 18(4): 95-101. 